\title{
Penyisipan Pesan Pada Citra Digital Menggunakan Metode Least Significant Bit
}

\author{
Muhammad Azlansyah dan Budi Setiyono \\ Departemen Matematika, Fakultas Matematika Komputasi dan Sains Data, \\ Institut Teknologi Sepuluh Nopember (ITS) \\ e-mail:mike09jhoni@gmail.com
}

\begin{abstract}
Abstrak-Berbagai macam teknik untuk melindungi informasi yang dirahasiakan telah banyak dilakukan. Steganografi adalah salah satu teknik yang digunakan dalam penyembunyian pesan kedalam sebuah media sedemikian sehingga manusia sulit menyadari keberadaan pesan tersebut. Pada studi ini teknik steganografi yang digunakan metode Least Significant Bit (LSB). Metode Least Significant Bit (LSB) adalah metode menyembunyikan pesan pada bit terakhir citra digital sehingga tidak terjadi perubahan secara kasat mata. Pada metode Least Significant Bit (LSB) dibutuhkan 3 input berupa citra, pesan, dan kunci. Pertama kunci dan pesan dirubah kedalam bentuk ASCII, setelah itu dirubah kedalam bentuk biner. Kemudian diambil channel merah (red) dari citra yang dirubah kedalam bentuk biner. Selanjutnya pesan dan kunci disisipkan pada citra tersebut. Terakhir citra yang telah disisipkan pesan disimpan dengan nama Stego-Image. Untuk uji coba paenulis menggunakan 3 citra dengan karakteristik yang berbeda, yaitu: citra langit yang cenderung homogen, citra wajah yang sedikit komplek, dan citra pemandangan yang lebih komplek. Disamping itu uji coba juga dilakukan pada 4 tipe citra yang berbeda, yaitu bmp, jpeg, png, dan tiff. Hasil yang dicapai pada studi ini, citra yang disisipkan pesan tidak mengalami perubahan bentuk secara kasat mata, nilai rata-rata PSNR dari keempat tipe citra tersebut untuk penyisipan teks 250 kata adalah sebagai berikut: citra langit $68.22975 \mathrm{~dB}$, citra wajah $72.228575 \mathrm{~dB}$, citra pemandangan $74.322525 \mathrm{~dB}$ dan pesan yang disisipkan dapat dikembalikan seperti semula saat proses ekstraksi.
\end{abstract}

Kata Kunci-Steganografi, Metode Leas Significant Bit (LSB), Citra Digital.

\section{PENDAHULUAN}

$\mathrm{D}$ dunia modern seperti sekarang ini, internet dan komputer telah banyak digunakan di banyak tempat sebagai alat komunikasi. Dengan adanya internet, kita dapat berkomunikasi secara mudah dari berbagai tempat, dimanapun, dan kapanpun. Akan tetapi, berkomunikasi jarak jauh mempunyai resiko yang besar. Kita tidak mengetahaui apakah pesan kita benar-benar sampai ke tangan orang yang kita tuju kemungkinan lain, data akan diretas oleh oknum untuk kepentingan yang tidak seharusnya. Hal inilah yang menuntut adanya pengamanan data agar tidak sampai dicuri oleh pihak lain. Oleh karena itu, pengguna teknologi semakin ramai mengembangkan suatu system pengamanan terhadap data yang biasa disebut kriptografi.

Dalam kriptografi muncul istilah steganograi, yaitu suatu teknik menyisipkan pesan ke dalam suatu media. Walaupun steganografi masih berkaitan dengan kriptografi, tapi teknik ini sangat berbeda. Kriptografi mengacak pesan sehingga tidak dimengerti apa isi pesan tersebut, sedangkan steganografi mnyembunyikan pesan sehingga tidak terlihat. Pesan dalam ciphertext hasil proses kriptografi mungkin akan menimbulkan kecurigaan, namun tidak pada pesan yang dibuat dengan steganografi.

Steganografi merupakan ilmu yang mempelajari tentang seni menyembunyikan pesan atau informasi. Steganografi dapat digolongkan sebagai salah satu bagian dari ilmu komunikasi. Pada era informasi digital, steganografi merupakan teknik dan seni menyembunyikan informasi dan data digital dibalik informasi digital lain, sehingga informasi digital yang sesungguhnya tidak kelihatan. Seni dan ilmu ini telah diterapkan sejak dahulu oleh orang Yunani kuno yang menyembunyikan pesan dengan cara membuat tato di kepala pembawa berita yang dibotaki dan menunggu sampai rambutnya tumbuh.

Teknik steganografi lainnya adalah dengan menggunakan invisible ink (tinta yang tidak tampak). Tulisan yang ditulis dengan menggunakan invisible ink ini hanya dapat dibaca jika kertas tersebut diletakkan di atas lampu atau diarahkan ke matahari. Ketika perang dunia pertama, orang Jerman menyembunyikan pesan dalam bentuk microdot, yaitu titiktitik yang kecil. Agen dapat membuat foto kemudian mengecilkannya sampai sekecil titik di tulisan dalam buku. Buku ini kemudian bisa dibawa-bawa tanpa ada yang curiga bahwa tanda titik di dalam tulisan dibuku itu berisi pesan ataupun citra.

Dalam steganografi ada beberapa metode yang dapat digunakan salah satunya adalah metode Least Significant $B i t(L S B)$. Metode $L S B$ merupakan teknik penyisipan pesan dalam steganografi dimana penyisipan pesan dilakukan dengan mengganti deretan bit-bit data yang paling belakang dalam segmen citra dengan deretan bit-bit pesan yang akan disisipkan.

\section{DASAR TEORI}

\section{A. Citra Digital}

Citra digital dapat didefinisikan sebagai sebuah fungsi 2 dimensi, $f(x, y)$ dimana $x$ dan $y$ adalah koordinat bidang datar 
dan harga fungsi $f$ disetiap pasangan koordinat $(x, y)$ disebut intensitas/level keabuan ( gray level) dari gambar dititik itu [1]. Citra digital merupakan suatu matriks dimana indeks baris dan kolomnya menyatakan suatu titik pada citra tersebut dan elemen matriksnya (yang disebut sebagai elemen gambar / pixel / piksel / pels / picture element) menyatakan tingkat keabuan pada titik tersebut [2]. Matriks pada citra digital berukuran $M$ (baris/tinggi) x $N$ (kolom/lebar).

\section{B. Citra Warna}

Red (Merah), Green (Hijau) dan Blue (Biru) merupakan warna dasar yang dapat diterima oleh mata manusia. Setiap piksel pada citra warna mewakili warna yang merupakan kombinasi dari ketiga warna dasar RGB. Setiap titik pada citra warna membutuhkan data sebesar 3 byte. Setiap warna dasar memiliki intensitas tersendiri dengan nilai minimum nol (0) dan nilai maksimum 255 (8 bit). Citra high color biasanya disebut citra warna 16 bit setiap pixelnya diwakili dengan 2 byte memory. Citra 16 bit memiliki warna 65.536 warna. Dalam formasi bitnya, nilai red dan blue mengambil tempat di 5 bit kanan dan kiri. Komponen green memiliki 5 bit ditambah 1 bit ekstra.

\section{Steganografi}

Kata steganografi berasal dari bahasa yunani, steganos yang artinya tersembunyi dan graphien yang artinya tulisan yang dapat diterjemahkan menjadi tulisan yang tersembunyi. Menurut Munir bahwa Steganografi didefinisikan sebagai ilmu dan seni untuk menyembunyikan pesan rahasia (hiding message) sedemikian sehingga keberadaan pesan tidak terdeteksi oleh indera manusia. Media yang digunakan umumnya merupakan suatu media yang berbedadengan media pembawa informasi rahasia, disinilah fungsi dari teknik steganography yaitu sebagai teknik penyamaran menggunakan media lain yang berbeda sehingga informasi rahasia dalam media awal tidak terlihat secara jelas. Umur steganografi hamper sama tuanya dengan kriptografi. Steganografitertua ditulis oleh Herodatus (485 - 525 BC), sejarawan Yunani padatahun $440 \mathrm{BC}$ di dalam buku Histories of Herodatus. Kisah perangantara kerajaan Persia dan rakyat Yunani.Herodatus menceritakan cara Histaiaeus mengirim pesan kepadaAristagoras dari Miletusuntuk melawan Persia.Caranya:dipilih beberapa budak. Kepala budak dibotaki, ditulisi pesan dengan cara tato, rambut budak dibiarkan tumbuh, budak dikirim dan di tempat penerima kepala budak digunduli agar pesan bisa dibaca [3]. Ada juga penggunaan steganografi pada perang dunia II dengan cara menggunakan teknik microdot. Pesan yang akan dikirim diperkecil sampai hanya terlihat seperti 1 titik. Kemudian titik itu disisipkan ke dalam buku. Sehingga sipembawa pesan seperti tidak membawa sesuatu hal yang rahasia.

Dalam penyembunyian pesan ada beberapa kriteria yang perlu diperhatikan:

1. Imperceptibility. Keberadaan pesan rahasia tidak dapat dipersepsi oleh indra.

2. Fidelity. Mutu media penampung tidak berubah banyak akibat penyisipan.
3. Recovery. Pesan yang disembunyikan harus dapat diungkap kembali agar sewaktu - waktu pesan rahasia dapat diambil kembali untuk digunakan lebih lanjut [4].

\section{Metode Least Significant Bit}

Least Significant Bit (LSB) merupakan salah satu teknik dalam Steganografi. LSB menambahkan bit data pesan yang akan disembunyikan di bit terakhir yang paling cocok atau kurang berarti. Misalkan bit pada image dengan ukuran 3 piksel sebagai berikut:

$$
\left(\begin{array}{lll}
0011111 & 11101001 & 11001000 \\
0011111 & 11001000 & 11101001 \\
1100000 & 00100111 & 11101001
\end{array}\right)
$$

Pesan yang akan disisipkan adalah karakter 'A' yang memiliki biner 10000001, stego image yang akan dihasilkan adalah:

$$
\left(\begin{array}{lll}
00111111 & 111010010 & 110010000 \\
00111110 & 110010000 & 111010010 \\
11000000 & 001001111 & 111010011
\end{array}\right)
$$

Ada dua teknik yang dapat digunakan pada LSB, yaitu penyisipan secara sekuensial dan secara acak. Penyisipan sekuensial dilakukan berurutan sedangkan acak dilakukan dengan acak pada image dengan memasukan kata kunci (stego key) [5].

\section{E. Metodologi}

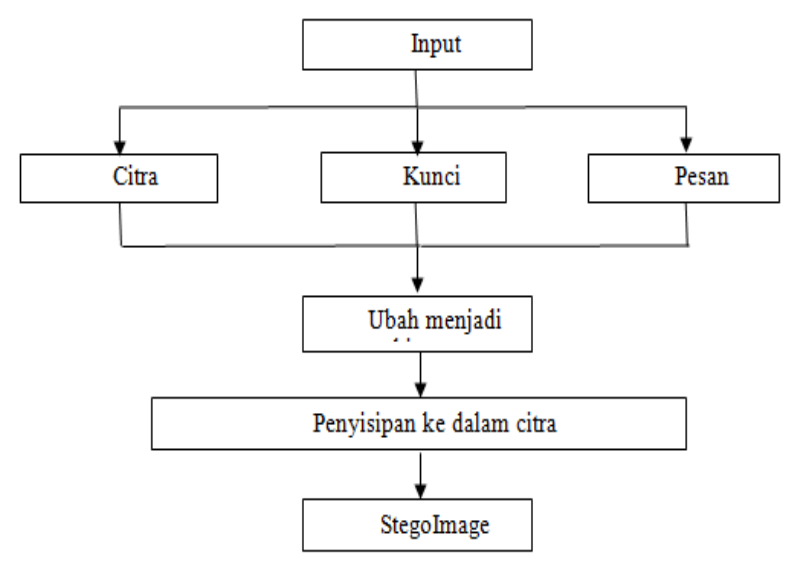

Gambar 1. Diagram alir proses penyisipan teks ke dalam citra.

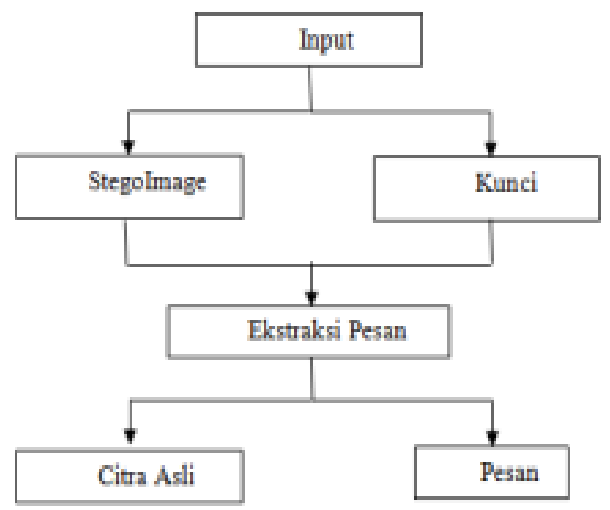

Gambar 2. Diagram alir proses ekstraksi pesan. 
Gambar 1 merupakan diagram alir proses penyisipan teks ke dalam citra. User menginputkan pesan, kunci dan citra. Kemudian pesan, kunci dan piksel citra dirubah menjadi kode biner. Selanjutnya pesan dan kunci disisipkan ke bit akhir citra dan disimpan sebagai StegoImage. Gambar 2 merupakan diagram alir proses ekstraksi pesan. User menginputkan citra yang telah disisipkan pesan (StegoImage) dan Kunci. Selanjutnya dilakukan proses ektraksi pesan sehingga didapat citra asli dan data teks yang disisipkan.

\section{PERANCANGAN DAN IMPLEMENTASI SISTEM}

\section{A. Analisa Sistem Perangkat Lunak}

Sistem perangkat lunak yang dirancang ini memiliki beberapa tahapan:

\section{Penyisipan Pesan}

Untuk memperjelas metode ini, maka akan diberikan contoh sebagai berikut:

Misalkan terdapat pesan "jul" dan kunci "R" yang memiliki kode ASCII sebagai berikut:

\begin{tabular}{|c|c|c|}
\hline 106 & 117 & 108 \\
\hline $\mathrm{j}$ & $\mathrm{u}$ & 1 \\
\hline
\end{tabular}

$$
\begin{array}{|c|}
\hline 82 \\
\hline \mathrm{R} \\
\hline
\end{array}
$$

Kemudian pesan dan kunci dirubah menjadi kode biner:

\begin{tabular}{|c|c|c|}
\hline 01101010 & 01110101 & 01101110 \\
\hline $\mathrm{j}$ & $\mathrm{u}$ & $\mathrm{l}$ \\
\hline
\end{tabular}

\begin{tabular}{|c|}
\hline 01010010 \\
\hline $\mathrm{R}$ \\
\hline
\end{tabular}

Misalkan citra yang akan digunakan sebagai wadah adalah citra "langit.jpg" (Gambar 3)

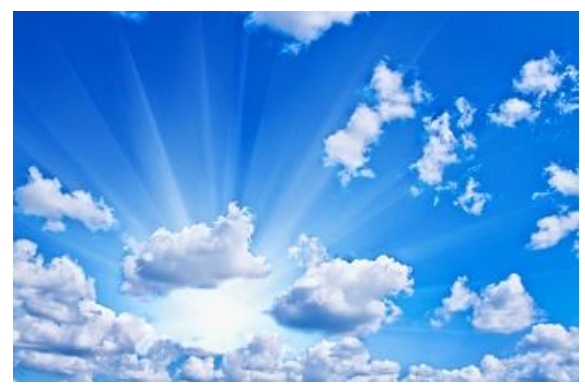

Gambar 3. Citra sebelum disisipkan pesan.

Dan misalkan diambil channel red (merah) untuk tempat menyisipkan pesan memiliki matriks 10 x 4 sebagai berikut:

$$
\left[\begin{array}{llllllll}
41 & 21 & 90 & 31 & 71 & 75 & 91 & 90 \\
65 & 51 & 81 & 66 & 74 & 79 & 95 & 93 \\
50 & 87 & 96 & 78 & 92 & 71 & 40 & 61 \\
65 & 43 & 76 & 82 & 99 & 78 & 72 & 39 \\
65 & 85 & 55 & 49 & 95 & 70 & 75 & 35 \\
73 & 67 & 50 & 47 & 69 & 77 & 45 & 34
\end{array}\right]
$$

Kemudian matriks di atas dirubah menjadi bentuk biner
$00101011 \quad 01000111 \quad 0110101001011010010110100110011001101001 \quad 00101101$ $\begin{array}{llllllll}01100110 & 01010101 & 01101100 & 01101110 & 01011101 & 01010111 & 00111010 & 00110111\end{array}$ $00110010 \quad 0101011101100000 \quad 0100111001011100 \quad 0100011100101000 \quad 00111101$ $\begin{array}{llllllll}01000001 & 00101011 & 01001100 & 01010010 & 01100011 & 01001110 & 01001000 & 00100111\end{array}$ 0100000101010101001101110011000101011111010001100100101100100011 0100100101000011001100100010111101000101010011010010110100100010

Selanjutnya kunci yang telah dirubah menjadi bentuk biner disisipkan ke elemen awal matriks citra yang telah dirubah menjadi kode biner

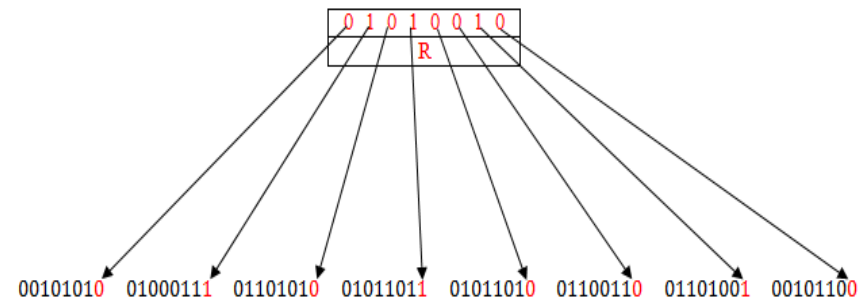

Selanjutnya penyisipan pesan yang telah dirubah menjadi bentuk matriks dimulai satu elemen setelah elemen terakhir kunci disisipkan
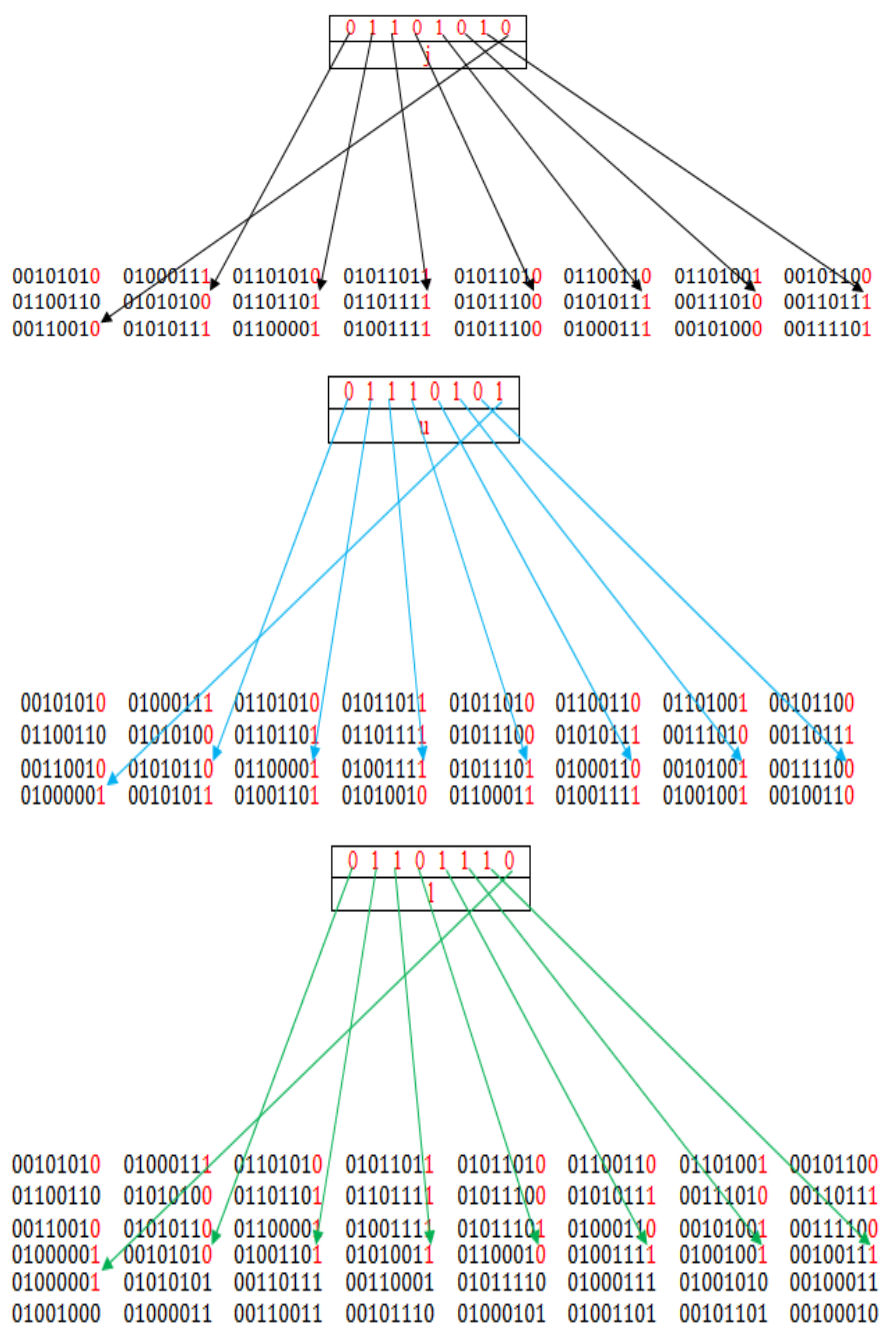

Kemudian matriks di atas dirubah kembali menjadi bentuk desimal 


$\begin{array}{llllllll}41 & 21 & 90 & 31 & 71 & 75 & 91 & 90 \\ 65 & 51 & 81 & 66 & 74 & 79 & 95 & 93 \\ 50 & 87 & 96 & 79 & 92 & 70 & 41 & 60 \\ 64 & 43 & 77 & 82 & 99 & 78 & 73 & 38 \\ 64 & 85 & 55 & 49 & 94 & 71 & 74 & 35 \\ 72 & 67 & 51 & 46 & 69 & 77 & 45 & 34\end{array}$

Terakhir simpan sebagai StegoImage.

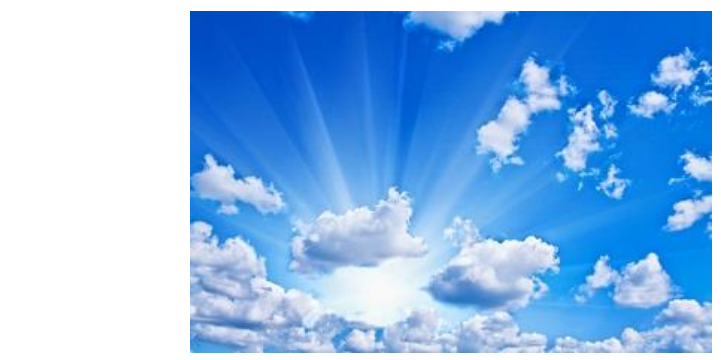

Gambar 4. Citra sesudah disisipkan pesan

\section{Ekstraksi Pesan}

Pada proses ektraksi, citra yang diinputkanadalahcitra yang telahdisisipkanpesan (Stego-Image)

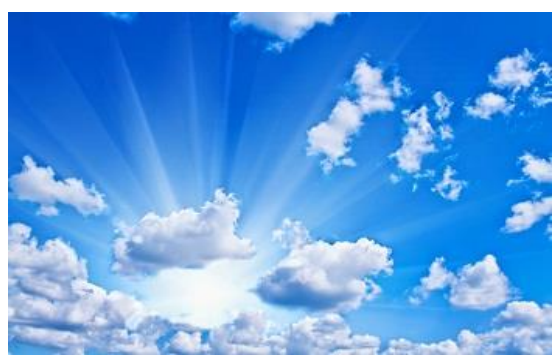

Gambar 5. Citra sesudah disisipkan pesan

$\left[\begin{array}{llllllll}41 & 21 & 90 & 31 & 71 & 75 & 91 & 90 \\ 65 & 51 & 81 & 66 & 74 & 79 & 95 & 93 \\ 50 & 87 & 96 & 79 & 92 & 70 & 41 & 60 \\ 64 & 43 & 77 & 82 & 99 & 78 & 73 & 38 \\ 64 & 85 & 55 & 49 & 94 & 71 & 74 & 35 \\ 72 & 67 & 51 & 46 & 69 & 77 & 45 & 34\end{array}\right]$.

Matriks di atas merupakan matriks dari Stego-Image, kemudian matriks dirubah menjadi bentuk biner menjadi:

0010101001000111011010100101101101011010011001100110100100101100 0110011001010100011011010110111101011100010101110011101000110111 0011001001010110011000010100111101011101010001100010100100111100 010000010010101001001101010100110110001001001111010010010010011 0100000101010101001101110011000101011110010001110100101000100011 0100100001000011001100110010111001000101010011010010110100100010 Lalu inputkan kunci

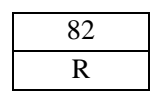

Kemudian kunci dirubah menjadi bentuk biner

\begin{tabular}{|c|}
\hline 01010010 \\
\hline $\mathrm{R}$ \\
\hline
\end{tabular}

Selanjutnya sistem akan menyocokkan kunci yang diinputkan dengan kunci yang ada dalam piksel citra. Apabila kunci sesuai maka sistem mengambil bit-bit pesan yang disisipkan. Terakhir, sistem mengubah bit-bit pesan menjadi teks dan menampilkannya pada perangkat lunak.

3.1 Pemrogaman

a. Implementasi Masukkan Citra

Masukkan pada perangkat lunak ini berupa citra warna 16 bit. Proses tersebut diimplementasikan dalam source code berikut :

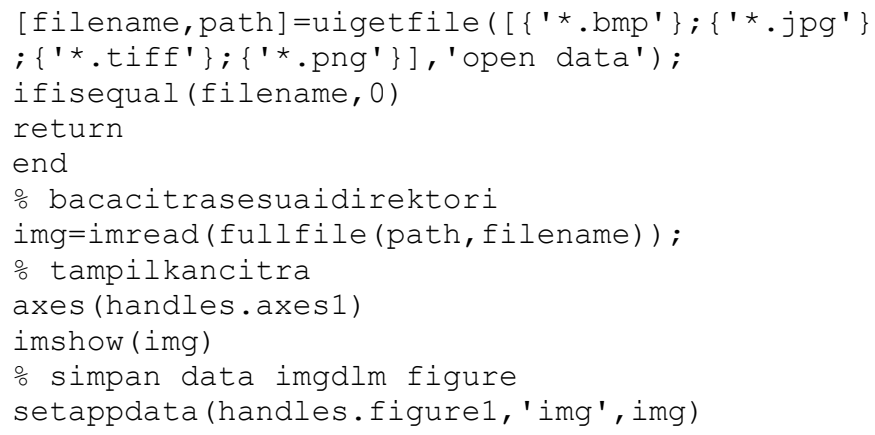

b. Implementasi Penyisipan Citra

Pada proses ini dilakukan penyisipan pesan setelah user memasukkan citra masukkan. Selanjutnya user memasukkan kunci dan pesan pada perangkat lunak dan proses penyisipan bisa dilakukan. Proses penyisipan diimplementasikan dalam sourcecode berikut:

$\mathrm{k}=0$;

fori $=1:$ size $(c, 2) \div$ lebar citra

for $j=1$ : size $(c, 1)$ o panjang citra $\mathrm{k}=\mathrm{k}+1$

ig $=c(j, i)$; $\frac{\circ}{0}$ baca nilai pixel citra baris ke I dan kolom ke $j$

bg $(k,:)=\operatorname{dec} 2 b i n(i g, 8)$; o ubah kebiner

if $(k<=\operatorname{size}(b, 1))$ o sisipkan sebanyak nilai

biner (text)

$\operatorname{bg}(:$, end $)=$ num $2 \operatorname{str}(b(k)) ;$ sisipkan dibagian

akhir array

end

o setelah penyisipan ubah kembali ke nilai desimal (pixel)

$d=(\log (k,:)) ;$

$\operatorname{hg}(k,:)=\operatorname{bin} 2 \operatorname{dec}(d)$;

end

end

$\mathrm{s}=$ reshape (hg, size(c)) ; \% ubah ukuran seperti citra awal

s=uint8(s); \% transpose dan ubah kenilai 8 bit ky=size $(b, 1) / 8$; o ukuran panjang nilai biner

$\operatorname{imgs}(:,:, 1)=s$; $\frac{\circ}{0}$ ubah chanel $r$ (merah)

dengannilaihasilpenyisipan

imgs (end, end, 1) =ky; o simpan jumlah nilai biner

imgs (end, end-1,1)=l; $\frac{\circ}{\circ}$ simpan jumlah panjang

kata

o tampilkan di axes 2

axes (handles.axes 2 )

imshow (imgs)

- simpan hasil penysisipan

[filename, path] =uiputfile $\left(\left[\left\{{ }^{\prime} \star . . b m p '\right\} ;\left\{\prime^{*} . j p g g^{\prime}\right\}\right.\right.$

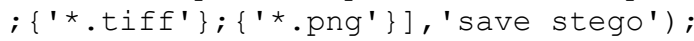

ifisequal (filename, 0 ) 
return

end

if strcmp (filename (:, end-2:end), 'bmp') | |

strcmp (filename ( : end-2: end), 'iff')

imwrite (imgs, fullfile (path, filename)) ;

else

imwrite (imgs, fullfile (path, filename),

'Mode', 'lossless');

end

c. Implementasi Ekstraksi Citra

Pada proses enkripsi masukan hanya ada 2 yaitu citra yang disisipi pesan dan kunci. Proses ekstraksi diimplementasikan dalam source code berikut :

\% ekstraksi

for $h=1: k y$

$\mathrm{si}=\mathrm{s}(\mathrm{h}, \mathrm{:})$; 응 baca pixel yang disiipkan

$\mathrm{db}=$ dec2bin $(\mathrm{si}, 8)$; $\frac{\circ}{0}$ ubahkebiner

$\mathrm{ds}(\mathrm{h},:)=\operatorname{str} 2 \mathrm{num}(\mathrm{db}(:$, end $)) ;$ o ubahkenumerik end

․ ubahkebiner string

for $\mathrm{k}=1: \operatorname{size}(\mathrm{ds}, 1)$;

$\mathrm{ib}=\mathrm{ds}(\mathrm{k})$;

if $(i b==1)$

$\operatorname{es}(\mathrm{k})=$ ' 1 ';

else

es $(\mathrm{k})=$ '0';

end

end

\% ubah kedalam ukuran biner awal

tx=reshape (es, $[8,1])$;

\% ubah nilai biner kedesimal kemudian di ubah

ke text

fori=1:size $(t x, 2)$

thisstring=char $(\operatorname{tx}(:, i))$ '; o baca nilai biner

string

thischar $(:, i)=\operatorname{char}($ bin2 dec $(($ thisstring $)))$;

ubah dari biner kedesimal kemudian ke text

(string)

end

\section{ANALISIS DAN PEMBAHASAN}

\section{A. Data Uji Coba}

Uji coba pada perangkat lunak dalam studi ini dilakukan terhadap 3 citra warna yang berbeda dan panjang kunci dan pesan yang disisipkan juga ada 3 jenis (Tabel 1).

\section{B. Pengujian Kualitatif}

Pengujian kualitatif dilakukan berdasarkan pengamatan visual dari citra yang disisipi pesan (Stego-Image). Dalam penelitian ini pengujian kualitatif dibagi menjadi 4 kriteria, yaitu:

1. Baik Sekali : Stego-Image tidak dapat dibedakan dengan citra asli.

2. Baik : Stego-Image dapat dibedakan dengan citra asli dengan pengamatan yang teliti.

3. Jelek : Stego-Image yang disisipi dapat dibedakan dengan citra asli dengan mudah.

4. Jelek Sekali : perbedaannya telihat jelas.

\section{Pengujian Penyisipan dan Ekstraksi Pesan}

Pada subbab ini dilakukan proses penyisipan dan ekstraksi pesan untuk menguji apakah kedua hal tersebut dapat
Tabel 1.

Data citra yang digunakan

\begin{tabular}{|c|c|c|c|}
\hline No. & Nama & Resolusi & Citra \\
\hline 1 & $\begin{array}{l}\text { Woodstock } \\
\text { vermont.jpg }\end{array}$ & $\begin{array}{c}736 x \\
490\end{array}$ & \\
\hline 2 & $\begin{array}{l}\text { Langit } \\
\text { Biru.jpg }\end{array}$ & $\begin{array}{c}350 x \\
229\end{array}$ & \\
\hline 3 & Bean.jpg & $\begin{array}{c}454 x \\
542\end{array}$ & \\
\hline
\end{tabular}

dilakukan untuk semua format citra. Hasil dari pengujian tersebut disajikan pada Tabel 2:

Tabel 2.

Hasil pengujian system pada proses penyisipan dan ekstraksi untuk semua format citra

\begin{tabular}{ccl}
\hline \multicolumn{3}{c}{ format citra } \\
\hline \hline Fomat Citra & Penyisipan & Ektraksi \\
\hline Png & Berhasil & Berhasil \\
Bmp & Berhasil & Berhasil \\
Jpg & Berhasil & Berhasil \\
Tif & Berhasil & Berhasil \\
\hline \hline
\end{tabular}

D. Pengujian Nilai PSNR (Peak Signal to Noise Ratio)

Tabel 3.

Hasil pengujian nilai $P S N R$ pada pengujian Pertama

\begin{tabular}{ccccc}
\hline \hline No. & Nama & Format & Stegoimage & $P S N R$ \\
\hline 1 & stego vermont 1 & Bmp & $1.03 \mathrm{MB}$ & $80.7642 \mathrm{~dB}$ \\
2 & stego vermont 2 & Jpg & $785 \mathrm{~KB}$ & $80.7716 \mathrm{~dB}$ \\
3 & stego vermont 3 & Tiff & $1.03 \mathrm{MB}$ & $81.7241 \mathrm{~dB}$ \\
4 & stego vermont 4 & Png & $624 \mathrm{~KB}$ & $81.7241 \mathrm{~dB}$ \\
5 & stego Bean 1 & Bmp & $197 \mathrm{~KB}$ & $78.8726 \mathrm{~dB}$ \\
6 & stego Bean 2 & Jpg & $85.6 \mathrm{~KB}$ & $78.8726 \mathrm{~dB}$ \\
7 & stego Bean 3 & Tiff & $88 \mathrm{~KB}$ & $78.7162 \mathrm{~dB}$ \\
8 & stego Bean 4 & Png & $100 \mathrm{~KB}$ & $78.7162 \mathrm{~dB}$ \\
9 & stego Langit Biru 1 & Bmp & $722 \mathrm{~KB}$ & $74.2547 \mathrm{~dB}$ \\
10 & stego Langit Biru 2 & Jpg & $15.5 \mathrm{~KB}$ & $74.2621 \mathrm{~dB}$ \\
11 & stego Langit Biru 3 & Tiff & $721 \mathrm{~KB}$ & $83.1329 \mathrm{~dB}$ \\
12 & stego Langit Biru 4 & Png & $191 \mathrm{~KB}$ & $83.1329 \mathrm{~dB}$ \\
\hline \hline
\end{tabular}

Tabel 4.

Hasil pengujian nilai $P S N R$ pada pengujian Kedua

\begin{tabular}{ccccc}
\hline \hline No. & Nama & Format & Stegoimage & $P S N R$ \\
\hline 1 & stego vermont 1 & Bmp & $1.03 \mathrm{MB}$ & $77.8809 \mathrm{~dB}$ \\
2 & stego vermont 2 & Jpg & $785 \mathrm{~KB}$ & $77.8961 \mathrm{~dB}$ \\
3 & stego vermont 3 & Tiff & $1.03 \mathrm{MB}$ & $77.6092 \mathrm{~dB}$ \\
4 & stego vermont 4 & Png & $624 \mathrm{~KB}$ & $77.6092 \mathrm{~dB}$ \\
5 & stego Bean 1 & Bmp & $197 \mathrm{~KB}$ & $75.9648 \mathrm{~dB}$ \\
6 & stego Bean 2 & Jpg & $85.6 \mathrm{~KB}$ & $75.9648 \mathrm{~dB}$ \\
7 & stego Bean 3 & Tiff & $88 \mathrm{~KB}$ & $75.1251 \mathrm{~dB}$ \\
8 & stego Bean 4 & Png & $100 \mathrm{~KB}$ & $75.1251 \mathrm{~dB}$ \\
9 & stego Langit Biru 1 & Bmp & $722 \mathrm{~KB}$ & $71.3568 \mathrm{~dB}$ \\
10 & stego Langit Biru 2 & Jpg & $15.5 \mathrm{~KB}$ & $71.3567 \mathrm{~dB}$ \\
11 & stego Langit Biru 3 & Tiff & $721 \mathrm{~KB}$ & $71.8211 \mathrm{~dB}$ \\
12 & stego Langit Biru 4 & Png & $191 \mathrm{~KB}$ & $71.7211 \mathrm{~dB}$ \\
\hline \hline
\end{tabular}


Tabel 5.

Hasil pengujian nilai $P S N R$ pada pengujian ketiga

\begin{tabular}{ccccc}
\hline \hline No. & Nama & Format & Stegoimage & $P S N R$ \\
\hline 1 & stego vermont 1 & Bmp & $1.03 \mathrm{MB}$ & $74.3684 \mathrm{~dB}$ \\
2 & stego vermont 2 & Jpg & $785 \mathrm{~KB}$ & $74.3819 \mathrm{~dB}$ \\
3 & stego vermont 3 & Tiff & $1.03 \mathrm{MB}$ & $74.2699 \mathrm{~dB}$ \\
4 & stego vermont 4 & Png & $624 \mathrm{~KB}$ & $74.2699 \mathrm{~dB}$ \\
5 & stego Bean 1 & Bmp & $197 \mathrm{~KB}$ & $72.5819 \mathrm{~dB}$ \\
6 & stego Bean 2 & Jpg & $85.6 \mathrm{~KB}$ & $72.587 \mathrm{~dB}$ \\
7 & stego Bean 3 & Tiff & $88 \mathrm{~KB}$ & $71.8727 \mathrm{~dB}$ \\
8 & stego Bean 4 & Png & $100 \mathrm{~KB}$ & $71.8727 \mathrm{~dB}$ \\
9 & stego Langit Biru 1 & Bmp & $722 \mathrm{~KB}$ & $68.0512 \mathrm{~dB}$ \\
10 & stego Langit Biru 2 & Jpg & $15.5 \mathrm{~KB}$ & $68.037 \mathrm{~dB}$ \\
11 & stego Langit Biru 3 & Tiff & $721 \mathrm{~KB}$ & $68.4154 \mathrm{~dB}$ \\
12 & stego Langit Biru 4 & Png & $191 \mathrm{~KB}$ & $68.4154 \mathrm{~dB}$ \\
\hline \hline
\end{tabular}

Pengujian PNSR (Peak Signal to Noise Ratio) digunakan untuk mengukur kualitas citra yang dihasilkan. Metode PNSR adalah ukuran perbandingan antara nilai piksel citra awal dengan nilai piksel pada StegoImage yang dihasilkan. Hasil dari pengujian nilai $P S N R$ disajikan pada Tabel 3-5:

Berdasarkan pengujian PSNR didapatkan bahwa nilai $P S N R$ di atas $30 \mathrm{~dB}$, berarti kualitas antara citra asli dengan StegoImage tidak mengalami perubahan yang signifikan. Jadi keberadaan dari file yang tersembunyi tidak mudah terdeteksi oleh indra penglihatan manusia.

\section{KESIMPULAN DAN SARAN}

Berdasarkan analisisi dari hasil pengujian perangkat lunak steganografi menggunakan metode Least Significant $B i t(L S B)$ ini, dapat ditarik kesimpulan sebagai berikut :

1. Hasil dari penerapan untuk penyisipan pesan rahasia pada gambar berjalan dengan baik. Pesan yang disisipkan pada citra dapat diperoleh kembali secara utuh atau dengan kata lain pesan yang disisipkan sebelum proses penyisipan dan setelah proses ekstraksi mempunyai hasil yang sama tanpa ada perubahan pesan.

2. Citra yang telah disisipkan pesan (Stegolmage) tidak mengalami perubahan yang signifikan dengan citra asli, sehingga secara kasat mata tidak dapat diketahui bahwa terdapat pesan rahasia pada citra tersebut.

3. Dari uji coba diperoleh hasil bahwa citra yang lebih komplek mempunyai hasil yang lebih baik, terbukti dengan memiliki rata-rata nilai PSNR $74.322525 \mathrm{~dB}$.

Berdasarkan hasil yang dicapai pada penelitian ini, ada beberapa hal yang penulis sarankan untuk pengembangan selanjutnya yaitu:

1. Pada penelitian ini penulis hanya menggunakan media citra digital sebagai media penampung, diharapkan untuk penelitian selanjutnya menggunakan media audio, video, dan lain sebagainya.

2. Program masih menyisipkan pesan dalam bentuk plaintext pada penelitian berikutnya diharapkan pesan tersebut terenkripsi.

\section{DAFTAR PUSTAKA}

[1] B. Rakmat and M. Fairuzabadi, "Steganografi menggunakan Metode Least Significant Bit dengan Kombinasi Algoritma Kriptografi Vigneredan RC4,” J. Din. Inform., vol. 5, no. 2, 2010.

[2] D. Chopra, "Lsb Based Digital Image Watermarking For Gray Scale Image," IOSR J. Comput. Eng., vol. 6, no. 1, pp. 36-41, 2012.

[3] Irfan, "Penyembunyian Informasi (steganography) Gambar Menggunakan Metode LSB (Least Signifcant Bit)," Rekayasa Teknol., vol. 5, no. 1, 2013.

[4] A. Muadzani, O. Nurhayati, and I. P. Windasari, "Penyisipan Media Teks dan Citra Menggunakan Teknik Steganografi pada Media Pembawa Citra Digital," J. Teknol. dan Sist. Komput., vol. 4, no. 3, pp. 470-478, 2016.

[5] M. Ineke Pakereng, Y. Richard Beeh, S. Endrawan, and U. Kristen Duta Wacana Yogyakarta, "Perbandingan Steganografi Metode Spread Spectrum dan Least Significant Bit (LSB) Antara Waktu Proses dan Ukuran File Gambar." 